\title{
The susceptibility of organisms associated with bacterial vaginosis to spermicidal compounds, in vitro
}

\author{
Brian $M$ Jones, Lorna $M$ Willcox
}

\begin{abstract}
Objectives-Bacterial vaginosis (BV) is a prevalent vaginal infection that is now regarded as a risk factor in more serious pelvic and obstetric complications. Spermicides are known to have antimicrobial activity against other sexually transmitted diseases and the aim of this study was to test whether the causative organisms of BV were also susceptible to spermicides, in vitro.
\end{abstract}

Design-Minimal Inhibitory Concentrations of five spermicidal compounds were determined for the organisms associated with $B V$, in an agar dilution technique.

Location-The Department of Experimental and Clinical Microbiology, University of Sheffield Medical School, UK.

Spermicides and Organisms-Nonoxynol-9, Nonoxynol-11, Docusate sodium, Benzalkonium chloride and Menfegol were tested against 20 strains each of Gardnerella vaginalis, Bacteroides and Mobiluncus organisms, isolated from patients with BV who attended the Department of Genitourinary Medicine, the Royal Hallamshire Hospital, Sheffield.

Main outcome measures-The susceptibility of BV-associated organisms to spermicidal compounds, in vitro.

Results-G vaginalis, Mobiluncus spp, Bacteroides bivius and Bacteroides disiens were all susceptible to the five spermicides tested, with MICs ranging between $\leqslant 19$ and $5000 \mathrm{mg} / 1(0.0019 \%-0.5 \%)$.

Conclusion-The concentrations of spermicides incorporated in contraceptive preparations are usually between $3 \%$ and $8 \%$, which are far in excess of the MICs found for BV organisms. Their usage could exert a significant antimicrobial effect and be a useful prophylactic in preventing the infection.

Department of Experimental and Clinical Microbiology, University of Sheffield Medical School, Beech Hill Road, Sheffield, S10 2RX, UK

Brian M Jones

The London International Group, PLC, Unit 203, Cambridge Science Park, Cambridge, CB4 4EZ, UK Lorna $M$ Willcox

\section{Introduction}

The active ingredients of spermicidal preparations are known to have antimicrobial activity in vitro against many of the causative agents of sexually transmitted diseases, including Treponema pallidum, Trichomonas vaginalis, Chlamydia trachomatis, Herpesvirus, types I and II, the Human Immunodeficiency Virus, Mycoplasma hominis, Ureaplasma urealyticum and Haemophilus ducreyi. ${ }^{12}$ Clinical studies have confirmed that spermicides, particularly when combined with the use of condoms or diaphragms, can also provide effective prophylaxis against these infections in vivo. ${ }^{3}$

Bacterial vaginosis (BV) has now become the commonest vaginal infection $\mathrm{known}^{4}$ and, so far, the susceptibility of its causative organisms to spermicide compounds has not been evaluated. This study determined the Minimal Inhibitory Concentration of five spermicidal compounds for Gardnerella vaginalis, Mobiluncus and Bacteroides organisms, in an agar-dilution technique.

Materials and methods

Spermicide compounds

The spermicide compounds tested were Nonoxynol9 (N-9), Nonoxynol-11 (N-11), Benzalkonium chloride (BZK), Sodium dodecyl sulpho-succinate (docusate sodium) and $\alpha$ ((p-methyl)W-hydroxypoly (Oxyethylene)-(Menfegol). All were supplied by the London International Group, PLC, Cambridge, CB4 4G7, UK.

\section{Culture media}

The medium used for culture and maintenance of the test strains was Columbia agar base, enriched with defibrinated horse blood, $7 \cdot 5 \%$ and, for MIC determinations, DST agar, enriched with lysed, defibrinated horse blood, 5\% (Oxoid Ltd, Basingstoke, RG24 0PW, UK).

\section{Organisms}

Twenty strains each of $G$ vaginalis, Mobiluncus and Bacteroides organisms were used in the study. All had been isolated from vaginal specimens, taken from patients with BV who had attended the Department of Genitourinary Medicine, the Royal Hallamshire 
Hospital, Sheffield. They were stored in liquid nitrogen vapour phase, at $-130^{\circ} \mathrm{C}$, prior to use.

\section{MIC determinations}

An agar-dilution method was used. The pure spermicide compounds were weighed and dissolved in sterile distilled water to make $10 \%$ stock solutions. A range of doubling dilutions were made, in $5 \mathrm{ml}$ volumes, to provide solutions from $10 \%$ to $0.019 \%$. Five $\mathrm{ml}$ of these dilutions, together with $2.5 \mathrm{ml}$ of lysed horse blood were added to $42.5 \mathrm{ml}$ molten and cooled DST agar and plates poured at concentrations ranging from $1 \%(10000 \mathrm{mg} / \mathrm{l})$ to $0.0019 \%(19 \mathrm{mg} /$ 1). To overcome solubility problems, plates containing $5 \%$ and $2.5 \%$ were prepared by adding the spermicides directly to molten DST agar.

Colonies of the organisms to be tested were suspended in sterile, physiological saline and diluted to circa $10^{9} \mathrm{cfu} / \mathrm{ml}$, by comparison with McFarland standard opacity tubes (API-bio Merieux Ltd, Basingstoke, RG22 6HY, UK), previously calibrated by surface viable counts. A multipoint inoculator (Denley Instruments Ltd, Billinghurst, RH14 9EY, UK) was used to deliver $0.001 \mathrm{ml}$ (circa $10^{6} \mathrm{cfu}$ ) to the surface of the spermicide-containing plates. $G$ vaginalis cultures were incubated at $37^{\circ} \mathrm{C}$, in an atmosphere of $10 \% \mathrm{CO}_{2}$ in air for two days: $\mathrm{Bac}-$ teroides and Mobiluncus spp were incubated at $37^{\circ} \mathrm{C}$, in an anaerobic cabinet (Don Whitley Scientific, Shipley, BD17 7SE, UK) in an atmosphere of $80 \%$ $\mathrm{N}_{2}, 10 \% \mathrm{H}_{2}$ and $10 \% \mathrm{CO}_{2}$, for two or four days, respectively. The MICs were recorded as the lowest concentration that prevented visible growth.

\section{Results}

MIC determination (table) showed $G$ vaginalis and Mobiluncus spp to be highly susceptible to all five spermicides, with benzalkonium chloride having the strongest activity. The susceptibility of Bacteroides organisms, however, was variable. All strains were highly susceptible to benzalkonium chloride and Docusate sodium but only nine of the 19 strains were susceptible to Nonoxynol-9, Nonoxynol-11 and Menfegol at concentrations of $1 \%$ or less. These susceptible strains, belonged to the $B$ bivius and $B$ disiens groups, the types most commonly found in $\mathrm{BV}$, whereas the relatively resistant strains were of the $B$ fragilis and $B$ oralis groups, which are not usually found in BV.

\section{Discussion}

Vaginal infections affect large numbers of women with a variety of symptoms and sequelae that vary widely in severity. BV is now the most prevalent and rather than merely being the cause of an unpleasant discharge, has become a risk factor in more serious pelvic and obstetric infections. ${ }^{4}$

This study has shown the organisms associated with BV to be susceptible to spermicide compounds, in vitro and the concentrations incorporated into contraceptive preparations, usually between $3 \%$ and $8 \%$, are far in excess of the MICs found for $G$ vaginalis, Mobiluncus and Bacteroides organisms. These in vitro findings suggest that the use of spermicides could exert a significant antimicrobial effect against BV, in vivo and, together with barrier

Table Minimum inhibitory concentrations of spermicide compounds against the organisms associated with Bacterial vaginosis, in vitro ( $\mathrm{mg} / \mathrm{l})$

\begin{tabular}{|c|c|c|c|}
\hline Spermicide & $\begin{array}{l}\text { G vaginalis } \\
(n=20)\end{array}$ & $\begin{array}{l}\text { Bacteroides spp } \\
(n=19)\end{array}$ & $\begin{array}{l}\text { Mobiluncus spp } \\
(n=20)\end{array}$ \\
\hline $\begin{array}{l}\text { Nonoxynol-9 } \\
\text { MIC range } \\
\text { MIC } 50 \\
\text { MIC }^{90}\end{array}$ & $\begin{array}{l}39-156 \\
78 \\
156\end{array}$ & $\begin{array}{l}39-50000 \\
25000 \\
50000\end{array}$ & $\begin{array}{l}39-156 \\
78 \\
156\end{array}$ \\
\hline $\begin{array}{l}\text { Nonoxynol-11 } \\
\text { MIC range } \\
\text { MIC } 50 \\
\text { MIC } \\
\text { Benzalkonium chloride }\end{array}$ & $\begin{array}{l}39-156 \\
156 \\
156\end{array}$ & $\begin{array}{l}39->50000 \\
25000 \\
>50000\end{array}$ & $\begin{array}{l}78-312 \\
78 \\
312\end{array}$ \\
\hline $\begin{array}{l}\text { MIC range } \\
\text { MIC } \\
\text { MIC } \\
\text { Docusate sodium }\end{array}$ & $\begin{array}{l}\leqslant 19 \\
\leqslant 19 \\
\leqslant 19\end{array}$ & $\begin{array}{l}\leqslant 19-39 \\
\leqslant 19 \\
39\end{array}$ & $\begin{array}{l}\leqslant 19 \\
\leqslant 19 \\
\leqslant 19\end{array}$ \\
\hline $\begin{array}{l}\text { MIC range } \\
\text { MIC } \\
\text { MIC } \\
\text { Menfegol }\end{array}$ & $\begin{array}{l}78-2500 \\
2500 \\
2500\end{array}$ & $\begin{array}{l}78-5000 \\
2500 \\
5000\end{array}$ & $\begin{array}{l}312-1250 \\
625 \\
1250\end{array}$ \\
\hline $\begin{array}{l}\text { Mic range } \\
\text { MIC }^{50} \\
\text { MIC }^{90}\end{array}$ & $\begin{array}{l}39-312 \\
156 \\
156\end{array}$ & $\begin{array}{l}\leqslant 19-\geqslant 10000 \\
\geqslant 10000 \\
\geqslant 10000\end{array}$ & $\begin{array}{l}78-156 \\
78 \\
156\end{array}$ \\
\hline
\end{tabular}

$\star 1 \%$ was the highest concentration tested. 
contraception, which has been shown previously to reduce the incidence of $\mathrm{BV},{ }^{5}$ could be effective prophylaxis in preventing the disease.

We are grateful to Mr I Geary and Mrs M E Lee for skilled technical help and to Mrs $\mathrm{H}$ Storer for her valuable secretarial assistance in preparing this manuscript. The financial support of the London International Group is gratefully acknowledged.

Address for correspondence: Dr B M Jones, Department of Experimental and Clinical Microbiology, University of Sheffield Medical School, Beech Hill Road, Sheffield, S10 2RX, UK.
1 Judson FN, Ehret JM, Bodin GF, Levin MJ, Reitmeijer AM. In vitro evaluations of condoms with and without Nonoxynol-9 as physical and chemical barriers against Chlamydia trachomatis, Herpes simplex virus 2 and Human Immunodeficiency virus. Sex Transm Dis 1989;16:51-6.

2 Jones BM, Geary I, Lee ME, Duerden BI. Susceptibility of Haemophilus ducreyi to spermicidal compounds, in vitro. Genitourin Med 1991;67:268-9.

3 Feldblum PJ, Fortney JA. Condoms, spermicides and the transmission of Human Immunodeficiency Virus: A review of the literature. Am J Public Health 1988;78:52-4.

4 Swedberg JA. Bacterial vaginosis: etiology, association with preterm labour, diagnosis and management. Compre Ther 1989;15:47-53.

5 Bramley HM, Dixon RA, Jones BM. Haemophilus vaginalis (Corynebacterium vaginale, Gardnerella vaginalis) in a family planning population. Br J Veneral Dis 1981;57:62-6.

Accepted for publication 9 September 1991 